\title{
Formulation and in-vitro bioequivalence evaluation of verapamil hydrochloride matrix tablets with Calan $R$
} \author{
Talha Jamshaid ${ }^{5}$ Muhammad A. Akram ${ }^{6}$ \\ ${ }^{1}$ College of Pharmacy, GC University of Faisalabad, 38000, Faisalabad, Pakistan \\ ${ }^{2}$ Faculty of Pharmacy, University of Central Punjab Lahore, 54000, Lahore, Pakistan \\ ${ }^{3}$ Faculty of Pharmacy, The University of Lahore, 54000, Lahore, Pakistan \\ ${ }^{4}$ Faculty of Pharmacy, The Islamia University of Bahawalpur, 63100, Bahawalpur, Pakistan \\ ${ }^{5}$ University of Lyon, France \\ ${ }^{6}$ Faculty of Pharmacy, University of Sargodha, 40100, Sargodha, Pakistan
}

*Irfan Bashir ${ }^{1,2}$, Ayesha Sethi ${ }^{1}$, Muhammad Zaman ${ }^{3}$, Junaid Qureshi ${ }^{1}$, Rai M. Sarfraz ${ }^{4}$, Asif Mahmood ${ }^{4}$, Muhammad I. Sajid²,

\begin{abstract}
The purpose of the current work was to formulate Verapamil Hydrochloride (VH) sustained release matrix tablets by using natural polymers and comparison with leading national brand Calan SR of Searle Pharmaceuticals. Tragacanth and pectin were used in various concentrations. Pre compression studies i.e. angle of repose, bulk density, tapped density, Carr's compressibility index and Hausner's ratio were also performed and found within the Pharmacopoeial limits. Eight formulations (F1-F8) of (VH) were prepared by direct compression method. Post compression studies i.e. Thickness, Hardness, Diameter, Friability and Dissolution studies were conducted. Different kinetic models i.e. zero order, first order, Highuchi model and Korsmeyer Peppas were applied to study release patterns and similarity index was calculated. Dissolution studies were carried out in phosphate buffer of $\mathrm{pH} 6.8$ showed that formulations (F4 and F8) formulated with higher polymers concentration showed comparatively better drug retardation. F5 was the most comparable with the reference product. Verapamil hydrochloride released was observed non-fickian as diffusion following Higuchi model.
\end{abstract}

Key Words: Verapamil hydrochloride, Calan SR, kinetic models, matrix tablets, natural polymers.

\section{INTRODUCTION}

Dosage forms are designed to deliver optimum dose of drug to the site of action to produce desired pharmacological action and also to achieve the effective drug concentration over the preferred period of time. Oral drug delivery system is the most commonly used route of administration when compared to all other routes for various pharmaceutical products of different dosage forms. Easy administration, high patient compliance, avoiding tough sterile standards, and relatively cheap and easy formulation makes the oral dosage form as the first priority (Krishnaiah et al., 2002). Verapamil Hydrochloride, a commonly used calcium channel blocker for hypertension and arrhythmias, has a biological half-life of 4 to 6 hours. It has quite good absorption profile from gastrointestinal tract; about $90 \%$ of the orally administered drug is absorbed from the gastro intestinal tract. However, it undergoes extensive first pass metabolism which results in only $20 \%$ bioavailability. Keeping in view these facts, formulating a controlled release dosage form for Verapamil Hydrochloride is gaining interest to increase the therapeutic efficacy and patient compliance (Sahoo et al., 2009). Matrix tablets can be formulated by using natural polymers by direct compression of the mixture of active ingredient, retardant material and additives. The hydrophilic matrix needs water to activate the release mechanism and several benefits including ease of manufacture, release of $100 \%$

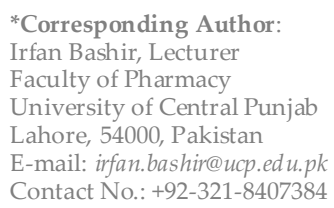

drug in-vivo and outstanding uniformity of matrix tablets. The hydrophilic matrix tablets are immersion in water swiftly forms a gel layer around the tablets (Shah et al., 2012).

Aims and objectives of the present study are to formulate the sustained release matrix tablets of Verapamil Hydrochloride using natural polymers (Tragacanth and Pectin) by direct compression method. Natural polymers exhibit good drug release retarding behavior and are biocompatible \& economic. Release retarding behavior of natural polymers in matrix formulations is compared to that of marketed product Calan SR taken as reference tablet.

\section{MATERIALS AND METHODS}

\section{Materials}

Verapamil Hydrochloride used as a model drug was gifted by Searle Pakistan Ltd. Microcrystalline cellulose (diluent), aerosil (glidant), magnesium stearate (lubricant) and polymers (release retarding materials) Pectin and Tragacanth were obtained as a gift from Unexo Pharma (pvt.) Ltd. Lactose was obtained from E Merck Germany. Chemicals like hydrochloric acid, sodium hydroxide, potassium dihydrogen phosphate were obtained from Mega Pharmaceuticals (pvt.) Ltd.

\section{Methods}

Milling of all ingredients was conducted to reduce the particle size then all the ingredients were passed through sieve no. 60. Verapamil hydrochloride was mixed with different polymers (individually as well as different combination forms) one by one in different drug to polymer ratios 1:0.5, 1:1, 1:1.5 and 1:2. Eight different Verapamil Hydrochloride - polymer combinations were 
Table 1: Composition of matrix tablets of Verapamil hydrochloride.

\begin{tabular}{|c|c|c|c|c|c|c|c|}
\hline Code & $\begin{array}{c}\text { Verapamil } \\
(\mathrm{mg})\end{array}$ & $\begin{array}{c}\text { Traga- } \\
\text { canth (mg) }\end{array}$ & $\begin{array}{l}\text { Pectin } \\
\text { (mg) }\end{array}$ & $\begin{array}{c}\text { Lactose } \\
\text { (mg) }\end{array}$ & $\begin{array}{l}\text { Mg. Stea- } \\
\text { rate (mg) }\end{array}$ & $\begin{array}{c}\text { Aerosil } \\
\text { (mg) }\end{array}$ & $\begin{array}{l}\text { PVP } \\
\text { (mg) }\end{array}$ \\
\hline F1 & 240 & 120 & - & 424 & 8 & 8 & 50 \\
\hline F2 & 240 & 240 & - & 304 & 8 & 8 & 50 \\
\hline F3 & 240 & 360 & - & 184 & 8 & 8 & 50 \\
\hline F4 & 240 & 480 & - & 64 & 8 & 8 & 50 \\
\hline F5 & 240 & - & 120 & 424 & 8 & 8 & 50 \\
\hline F6 & 240 & - & 240 & 304 & 8 & 8 & 50 \\
\hline F7 & 240 & - & 360 & 184 & 8 & 8 & 50 \\
\hline F8 & 240 & - & 480 & 64 & 8 & 8 & 50 \\
\hline
\end{tabular}

made as shown in (table 1), which were then mixed with PVP, Aerosil and lactose in a poly bag and the mixture was again passed through a mesh no. 60. Magnesium Stearate was added to the blend. Twenty different blends thus obtained were weighed individually for weightequivalent to $850 \mathrm{mg} /$ tablet and then were compressed into tablets on a single punch tablet machine.

\section{Pre-compression studies}

Angle of repose

Blend of powder was added to a funnel that was vertically placed to obtain a max height $(\mathrm{H})$ cone. Radius of heap $(\mathrm{R})$ was noted and $(\Theta)$ angle of repose was calculated as (Marshal, 1987).

$\Theta=\tan ^{-1}(\mathrm{H} / \mathrm{R})$

\section{Bulk density}

Drug and excipients mixture was sieved and then put in the graduated cylinder. The volume and weight of powder was determined (Marshal, 1987).

Bulk density= weight of powder/volume of powder

\section{Tapped density}

The tapped density was determined by tapping the cylinder having pre-weighed powder and then tapped it 100 times (Marshal, 1987).

$\mathrm{Db}=\mathrm{W} / \mathrm{Vb}$

$\mathrm{Db}=$ loose bulk density, $\mathrm{W}=$ weight of powder, $\mathrm{Vb}=$ volume of powder

\section{Carr's index}

The free flowing of powder was measured by compressibility index i.e. a property with which material would flow easily (Marshal, 1987).

Carr's index $(\mathrm{I})=(\mathrm{Vb}-\mathrm{Vt}) \times 100 / \mathrm{Vb}$

\section{Hausner ratio}

It is indirect method for measuring ease of powder flow (Marshal, 1987).

\section{Hausner's ratio $=\mathrm{Dt} / \mathrm{Db}$}

\section{DSC studies}

The DSC analysis of pure drug, polymers and there mixture was conducted on SDT. Q600 TA USA to check any possible interactions. Drug, polymers and there combinations were triturated to make them fine in size and then heated in sealed Aluminium pan at a heating rate of $10^{\circ} \mathrm{C} / \mathrm{min}$ from 0 to $210^{\circ} \mathrm{C}$. The nitrogen flow was $40 \mathrm{ml} / \mathrm{min}$. Reproducibility was checked by running sample in triplicate (Ranjha et al., 2010).
Table 2: Results of bulk density, tapped density, angle of repose, Hausner's ratio and Carr's index.

\begin{tabular}{cccccc}
\hline Code & $\begin{array}{c}\text { Bulk density } \\
(\mathrm{g} / \mathbf{m l})\end{array}$ & $\begin{array}{c}\text { Tapped } \\
\text { density }(\mathrm{g} / \mathbf{m l})\end{array}$ & $\begin{array}{c}\text { Angle of } \\
\text { repose }\left({ }^{\circ}\right)\end{array}$ & $\begin{array}{c}\text { Hausner's } \\
\text { ratio }\end{array}$ & $\begin{array}{c}\text { Carr's } \\
\text { index (\%) }\end{array}$ \\
\hline F1 & 0.675 & 0.782 & 24.5 & 1.15 & 16.30 \\
F2 & 0.665 & 0.778 & 25.8 & 1.16 & 15.20 \\
F3 & 0.65 & 0.750 & 23.6 & 1.15 & 15.78 \\
F4 & 0.635 & 0.750 & 25.7 & 1.18 & 15.53 \\
F5 & 0.679 & 0.790 & 24.6 & 1.16 & 16.10 \\
F6 & 0.670 & 0.780 & 24.5 & 1.16 & 15.38 \\
F7 & 0.655 & 0.772 & 25.6 & 1.17 & 16.35 \\
F8 & 0.660 & 0.788 & 26.0 & 1.19 & 15.90 \\
\hline
\end{tabular}

\section{Post-compression studies}

Compressed tablets were evaluated by different parameters, including appearance, thickness and diameter, weight variations, hardness, percent friability and contents uniformity (Patel et al., 2012).

\section{Dissolution studies}

Dissolution studies of Verapamil Hydrochloride tablets were investigated in USP tablet dissolution test apparatusII (Paddle apparatus) at $50 \mathrm{rpm} .900 \mathrm{ml}$ of $\mathrm{pH} 6.8$ phosphate buffer was used as a dissolution medium. An already warmed to $37 \pm 0.5^{\circ} \mathrm{C}$ dissolution medium was used and its temperature was maintained during the complete time of experiment. Five $\mathrm{ml}$ of the sample of dissolution medium was taken using syringe at specified time intervals (1 hour). The volume withdrawn at each interval was replaced with same quantity of fresh dissolution medium. The sample was analyzed for drug release by measuring the absorbance at $278 \mathrm{~nm}$ using UV-visible spectrophotometer after suitable dilutions and filtration.

\section{Statistical analysis}

Statistical analysis was done to calculate the standard deviation and mean of different parameters. Different kinetics modes were applied including;

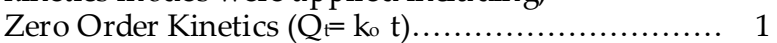

First Order Kinetics $\left(\log Q_{t}=\log Q_{o}-k_{1} t\right) \ldots \ldots \ldots \ldots$.

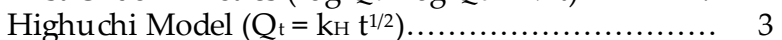
KorsmeyerPeppas Model $\left(\mathrm{M}_{\mathrm{t}} / \mathrm{M}_{\infty}=\mathrm{kKFt}^{\mathrm{n}}\right) \ldots \ldots \ldots \ldots . . .4$

These models were utilized in the prediction of drug behavior and release kinetics (Sahoo et al., 2009). Similarity (f2) and difference (f1) factors were also calculated by the following equations (Shah et al., 2009; Gohel et al., 2002).

$$
\begin{aligned}
& f 1=\frac{\sum\left[R_{t}-T_{t}\right]}{\sum R_{t}} \times 100 \\
& f 2=50 \cdot \log \left[\frac{1}{\sqrt{1+\frac{1}{n}} \sum\left(R_{t}-T_{t}\right)^{2}} \times 100\right]
\end{aligned}
$$

\section{RESULTS}

\section{Pre-compression studies}

All the results of angle of repose, bulk density, tapped density; Carr's compressibility index and Hausner's ratio were found within the limits indicating good flow properties of powder to be compressed as shown in (table 2). Differential scanning calorimetery (DSC) was performed for all the polymers and drug alone and in combination, no compatibility issue was revealed from spectra as shown in (figure 1). 


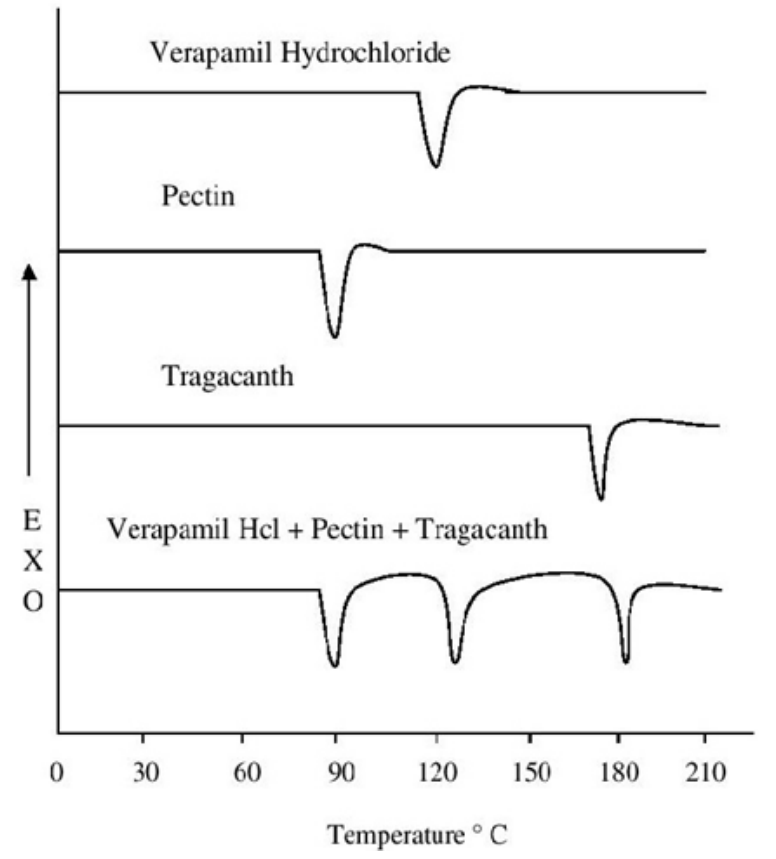

Figure 1: DSC Spectrum of drug and polymers.

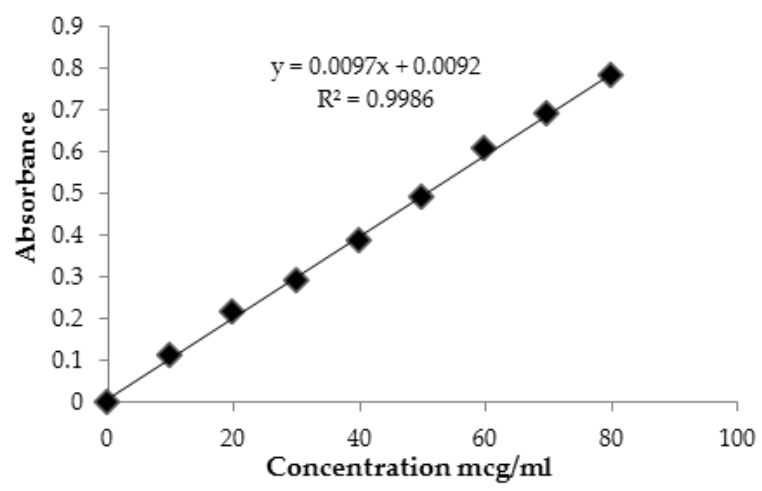

Figure 2: Calibration Curve for Verapamil hydrochloride.

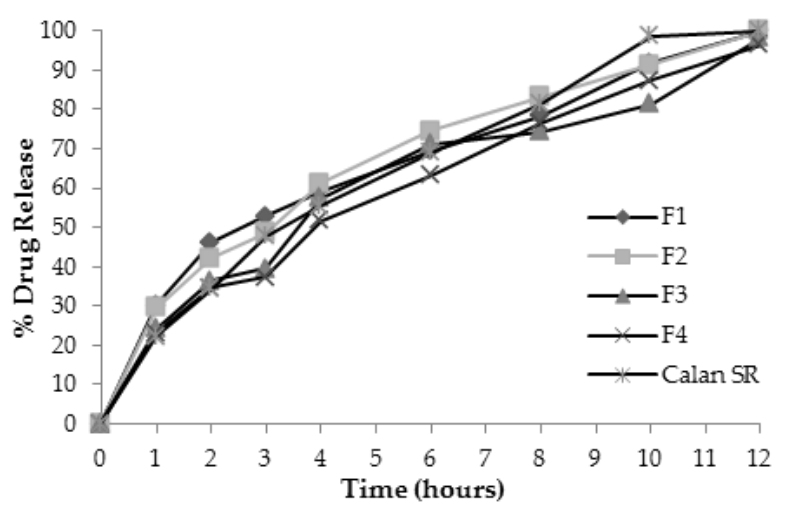

Figure 3: Drug release pattern of F1-F4 Compared to Calan SR.

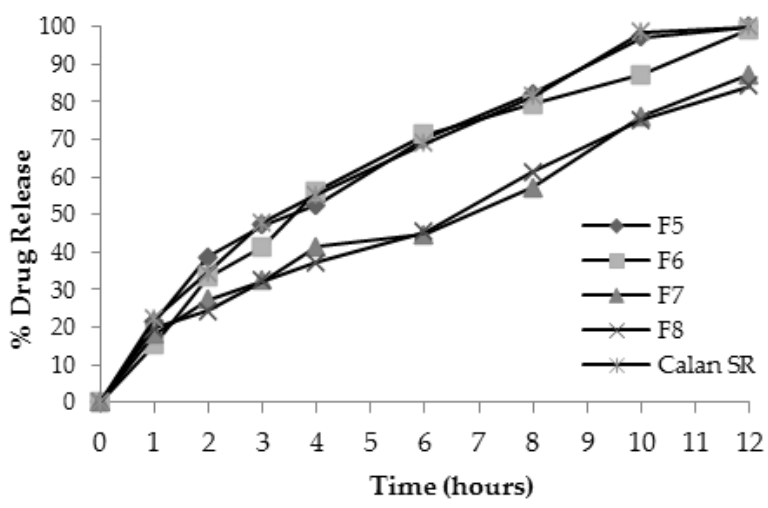

Figure 4: Drug release pattern of F5-F8 Compared to Calan SR.

Table 3: Post compression evaluation of VH matrix tablets.

\begin{tabular}{ccccc}
\hline Formulation & $\begin{array}{c}\text { Hardness } \\
\left(\mathbf{k g} / \mathbf{c m}^{\mathbf{2}} \mathbf{)}\right.\end{array}$ & $\begin{array}{c}\text { Thickness } \\
\mathbf{( m m )}\end{array}$ & $\begin{array}{c}\text { Drug } \\
\text { content } \mathbf{( \% )}\end{array}$ & $\begin{array}{c}\text { Friability } \\
\mathbf{( \% )}\end{array}$ \\
\hline F1 & $6.4 \pm 0.45$ & $7.33 \pm 0.02$ & $97.50 \pm 0.66$ & $0.45 \pm 0.03$ \\
F2 & $5.8 \pm 0.30$ & $7.24 \pm 0.04$ & $97.75 \pm 0.24$ & $0.33 \pm 0.01$ \\
F3 & $6.2 \pm 0.35$ & $7.30 \pm 0.03$ & $98.30 \pm 0.18$ & $0.50 \pm 0.03$ \\
F4 & $6.0 \pm 0.40$ & $7.35 \pm 0.05$ & $97.95 \pm 0.56$ & $0.40 \pm 0.02$ \\
F5 & $7.1 \pm 0.52$ & $7.27 \pm 0.03$ & $99.90 \pm 0.45$ & $0.25 \pm 0.02$ \\
F6 & $6.6 \pm 0.45$ & $7.28 \pm 0.02$ & $98.60 \pm 0.35$ & $0.52 \pm 0.01$ \\
F7 & $4.8 \pm 0.55$ & $7.33 \pm 0.03$ & $99.00 \pm 0.75$ & $0.44 \pm 0.04$ \\
F8 & $7.4 \pm 0.44$ & $7.29 \pm 0.04$ & $98.50 \pm 0.56$ & $0.45 \pm 0.02$ \\
Calan SR & $7.0 \pm 0.56$ & $7.26 \pm 0.01$ & $99.50 \pm 0.40$ & $0.30 \pm 0.03$ \\
\hline
\end{tabular}

Post compression studies

Hardness, thickness, percentage drug release and friability of all the formulations was found between 4.8$7.4 \mathrm{~kg} / \mathrm{cm}^{2}, \quad 7.24-7.35 \mathrm{~mm}, 97.50-99.90 \%$ and $0.25-0.50 \%$ respectively, as shown in table 3 .

Standard calibration curve for Verapamil hydrochloride Standard calibration curve was plotted for Verapamil Hydrochloride was plotted by taking concentration in $\mathrm{mcg} / \mathrm{ml}$ and measuring their absorbance at UV- visible Spectrophotometer. The standard calibration curve obtained was a straight line, which proved that the drug in the concentration range of $10-80 \mathrm{mcg} / \mathrm{ml}$, obeyed the Beer's Lambert law as shown in (figure 2).

\section{Dissolution studies}

Formulations F1-F4 formulated with tragacanth showed $100,100,98.25$ and $96.48 \%$ drug, respectively in 12 hours studies as shown in (figure 3). Formulations F5-F8 formulated with Pectin released 100, 99.37, 87.14 and $84.15 \%$ of the drug respectively in 12 hours (figure 4 ).

\section{Kinetics modeling of the release data}

Values of $\mathrm{R}^{2}$ for Zero order kinetics were 0.9023 to 0.9765 for First order kinetics were 0.8215 to 0.9624 , for Higuchi model 0.9613 to 0.9976 and for Peppas model these values were 0.9747 to 0.9960 while for reference tablets these values were $R^{2}=0.9504$ for Zero order kinetics, $R^{2}=0.8907$ for First order kinetics, $\mathrm{R}^{2}=0.9891$ for Higuchi model and $\mathrm{R}^{2}=0.9948$ for Peppas model as shown in (table 4).

\section{Similarity in dex}

Values of similarity factor $\left(\mathrm{f}_{2}\right)$ were found to be greater than 50 in all formulations except F7 and F8. Similarly the difference factor $\left(f_{1}\right) \leq 10$ for all the formulations except F7 and F8 as shown in (table 5). 
Table 4: Results of kinetic models data for F1-F8 in comparison with Calan SR.

\begin{tabular}{|c|c|c|c|c|}
\hline Trial & Zero Order Kinetics & First Order Kinetics & Higuchi Equation & Peppas Model \\
\hline F1 & $\begin{aligned} \mathrm{K} & =7.106 \\
\mathrm{R}^{2} & =0.9023\end{aligned}$ & $\begin{array}{c}\mathrm{K}=0.3016 \\
\mathrm{R}^{2}=0.8634\end{array}$ & $\begin{aligned} \mathrm{K} & =28.178 \\
\mathrm{R}^{2} & =0.9938\end{aligned}$ & $\begin{aligned} \mathrm{n} & =0.4525 \\
\mathrm{R}^{2} & =0.9916\end{aligned}$ \\
\hline $\mathrm{F} 2$ & $\begin{aligned} \mathrm{K} & =7.3986 \\
\mathrm{R}^{2} & =0.9141\end{aligned}$ & $\begin{array}{c}\mathrm{K}=0.3103 \\
\mathrm{R}^{2}=0.8943\end{array}$ & $\begin{aligned} K & =29.203 \\
R^{2} & =0.9976\end{aligned}$ & $\begin{array}{l}n=0.4995 \\
\mathrm{R}^{2}=0.996\end{array}$ \\
\hline F3 & $\begin{aligned} \mathrm{K} & =7.1348 \\
\mathrm{R}^{2} & =0.9285\end{aligned}$ & $\begin{array}{c}K=0.2543 \\
R^{2}=0.8276\end{array}$ & $\begin{aligned} K & =27.719 \\
\mathrm{R}^{2} & =0.9816\end{aligned}$ & $\begin{array}{c}\mathrm{n}=-0.5694 \\
\mathrm{R}^{2}=0.9779\end{array}$ \\
\hline F4 & $\begin{array}{c}\mathrm{K}=7.3861 \\
\mathrm{R}^{2}=0.9605\end{array}$ & $\begin{array}{c}\mathrm{K}=0.2371 \\
\mathrm{R}^{2}=0.9272\end{array}$ & $\begin{array}{c}K=28.281 \\
R^{2}=0.9863\end{array}$ & $\begin{array}{c}\mathrm{n}=0.6028 \\
\mathrm{R}^{2}=0.9863\end{array}$ \\
\hline F5 & $\begin{array}{c}\mathrm{K}=8.0585 \\
\mathrm{R}^{2}=0.9476\end{array}$ & $\begin{aligned} K & =0.3538 \\
R^{2} & =0.9144\end{aligned}$ & $\begin{array}{c}\mathrm{K}=31.127 \\
\mathrm{R}^{2}=0.9903\end{array}$ & $\begin{array}{c}\mathrm{n}=0.6199 \\
\mathrm{R}^{2}=0.9907\end{array}$ \\
\hline F6 & $\begin{array}{c}K=8.0495 \\
R^{2}=0.9429\end{array}$ & $\begin{array}{c}K=0.3256 \\
R^{2}=0.8215\end{array}$ & $\begin{array}{c}\mathrm{K}=31.032 \\
\mathrm{R}^{2}=0.9815\end{array}$ & $\begin{array}{c}\mathrm{n}=0.7215 \\
\mathrm{R}^{2}=0.9747\end{array}$ \\
\hline F7 & $\begin{array}{c}\mathrm{K}=6.5472 \\
\mathrm{R}^{2}=0.9722\end{array}$ & $\begin{array}{c}\mathrm{K}=0.1472 \\
\mathrm{R}^{2}=0.9294\end{array}$ & $\begin{array}{c}\mathrm{K}=24.6 \\
\mathrm{R}^{2}=0.9613\end{array}$ & $\begin{array}{c}\mathrm{n}=0.6281 \\
\mathrm{R}^{2}=0.9759\end{array}$ \\
\hline F8 & $\begin{array}{c}\mathrm{K}=6.4654 \\
\mathrm{R}^{2}=0.9765\end{array}$ & $\begin{aligned} K & =0.1385 \\
R^{2} & =0.9624\end{aligned}$ & $\begin{array}{c}\mathrm{K}=24.343 \\
\mathrm{R}^{2}=0.9696\end{array}$ & $\begin{aligned} \mathrm{n} & =0.598 \\
\mathrm{R}^{2} & =0.9747\end{aligned}$ \\
\hline Calan SR & $\begin{aligned} K & =7.9985 \\
R^{2} & =0.9504\end{aligned}$ & $\begin{aligned} K & =0.3738 \\
R^{2} & =0.8907\end{aligned}$ & $\begin{array}{l}K=30.832 \\
R^{2}=0.9891\end{array}$ & $\begin{array}{l}n=-0.6245 \\
R^{2}=0.9948\end{array}$ \\
\hline
\end{tabular}

\section{DISCUSSION}

Results of the thickness test and diameters were with minimal variations found to be uniform. Weight variations for formulations comply with the official limits \pm 5 . Formulation F4 showed least hardness value $5.7 \mathrm{~kg} / \mathrm{cm}^{2}$. Hardness, \% friability and drug contents of all the formulated tablets of verapamil hydrochloride complies with the official limits of $4-10 \mathrm{~kg} / \mathrm{cm}^{2}$, less than $1 \%$ and 95 $105 \%$ respectively as per BP. Formulation trials having least polymer ratios showed least release retarding behavior, but as the ratio of polymer to drug was increased, release retarding behavior also increased significantly. F4 Formulation having drug to polymer ratio $1: 2$, showed satisfactory sustained release behavior comparable to that of marketed product Calan SR. Release retarding behavior of drug in F7 \& F8 is much significant as compared to Calan SR but it did not comply with the official limits of USP. As the drug to polymer ratio was increased the similarity between F1 to F4 also increased but the formulation F3 showed some anomalous behavior. Although Formulation F3 is similar to marked product Calan SR, but the similarity factor value is less as compared to the formulation F1, F2 \& F4. Formulation F4 was the most similar formulation to that of the reference standard. Formulation F5 showed maximum similarity with reference formulation. With the increase of polymer concentration, release retarding behavior increased. Although F6, F7, F8 were more sustained than reference formulation, but similarity factor value decreased with the increase of drug to polymer ratios. Release of the drug was observed to be influenced by the polymer concentration as, polymers concentration increased the release of the drug decreased (Patel et al., 2012). Both tragacanth and pectin were the hydrophilic polymers. Initially there was greater release was observed because less hydration of the polymer but when the polymers in the tablets got hydrated release of the drug became slow gradually (Patel et al., 2012; Shah et al., 1998). Pectin became swell after the absorption of the aqueous media (Shah et al., 2011). Slow release was observed in the formulations containing pectin because of the formation of gel layer around the tablets which can decrease the rate of erosion of the tablets

Table 5: Results of trials F1-F8 in comparison with Calan SR.

\begin{tabular}{cccc}
\hline Formulation & $\begin{array}{c}\text { Difference } \\
\text { factor (f1) }\end{array}$ & $\begin{array}{c}\text { Similarity } \\
\text { factor (f2) }\end{array}$ & $\begin{array}{c}\text { Difference between } \\
\text { ref. and std. drug }\end{array}$ \\
\hline F1 & 9.85925 & 58.599 & Less than 10\% \\
F2 & 10.236 & 59.5458 & -do- \\
F3 & 10.4346 & 53.409 & -do- \\
F4 & 7.18469 & 61.5822 & -do- \\
F5 & 3.44509 & 79.2344 & Less than 10\% \\
F6 & 7.65385 & 60.6756 & -do- \\
F7 & 24.6019 & 39.1549 & More than 10\% \\
F8 & 25.5779 & 38.8556 & -do- \\
\hline
\end{tabular}

(Sriamornsak et al., 2007). Higher values of Higuchi model showed that drug release pattern was according to diffusion, which was usually observed in the matrix systems formulated with the natural hydrophilic polymers. Diffusional exponent value (n) of Pappas model for formulation trials F1-F2 showed quasi Fickian type of diffusion. Drug to polymer ratio in these formulations was 1:0.5 and 1:1 respectively. Polymer used in F1 to F4 formulations was pectin in different drug to polymer ratios. The percentages of polymer in F1\& F2 were $14.11 \%$ \& $28.23 \%$, respectively. Diffusional exponent value showed that at below $28 \%$ polymer concentration, pectin diffuses with a quasi-Fickian diffusion mechanism from a matrix tablet. Formulation trials F3, F4 \& standard formulation Calan SR followed anomalous or non-Fickian diffusion mechanism of drug. F3 \& F4 formulations were having $42 \%$ \& $56 \%$ pectin polymers respectively. Diffusional exponent value (n) of Pappas model for formulation trials F5-F8 \& standard formulation Calan SR showed non Fickian type of diffusion. Formulation F5 showed closed similarity with marketed product Calan SR. 


\section{REFERENCES}

Gohel, M.C. \& Panchal, M.K. (2002). Novel use of similarity factors $\mathrm{f} 2$ and $\mathrm{Sd}$ for the development of diltiazem $\mathrm{HCl}$ modified-release tablets using a 32 factorial design. Drug Development and Industrial Pharmacy, Volume 28, Issue 1, Pages, 77-87.

Krishnaiah, Y.S.R., Karthikeyan, R.S., Bhaskar, P., \&Satyanarayana, V. (2002).Bioavailability studies on guar gum-based three-layer matrix tablets of trimetazidinedihydrochloride in human volunteers. Journal of controlled release, Volume83, Issue 2, Pages 231-239. [DOI]

Marshall, K., Lachman, N. \&Liberman, H.A. (1987). The theory and practice of industrial pharmacy, 3rd ed., 67-85. Mumbai: Varghese Publishing House.

Patel, Anand, Modasiya, M., Shah, D. \& Patel, V (2009). Development and in vivo floating behavior of verapamil $\mathrm{HCl}$ intragastric floating tablets." AAPS Pharmaceutical Science \& Techology, Volume 10, Issue 1 ,Pages 310-315.

Ranjha, N.M., Khan, H. \& Naseem, S. (2010). Encapsulation and characterization of controlled release flurbiprofen loaded microsphere using beeswax as an encapsulating agent. Journal of Material Science: Material Medicine, Volume 21, Issue 1, Pages 1-10.

Sahoo, A., Murthy, P.N., Biswal, S., \& Manik. (2009). Formulation of sustained-release dosage form of verapamil hydrochloride by solid dispersion technique using eudragit RLPO or Kollidon ${ }^{\circledR}$ SR. AAPS Pharmaceutical Science and Technology, Volume 10, Issue 1, Pages 27 33.
Shah, B.M., Panda, S. \& Reddy, C.U.(2012). Formulation and evaluation of sustained release matrix tablets of verapamil hydrochloride by melt granulation. International Journal of Pharmacy and Pharmaceutical Sciences, Volume 4, Issue 3, Pages 501 - 506.

Shah, N., Shah, T. \& Amin, A. (2011). In-vitro Evaluation of pectin as a compression coating material for colon targeted drug delivery. International Journal of Pharmaceutical and Biological Sciences, Volume 2, Issue 2, Pages 410-418.

Shah, S.N., Asghar, S., Choudhry, M.A., Akash, M.S.H., Rehman, N.U. \&Baksh, S. (2009). Formulation and evaluation of natural gum-based sustained release matrix tablets of flurbiprofen using response surface methodology. Drug Development and Industrial Pharmacy, Volume 35, Issue 12, Pages, 1470-1478. [DOI]

Shah, V.P., Tsong, Y., Sathe, P. \& Liu, J.P. (1998). In vitro dissolution profile comparison and analysis of similarity factor f2. Pharmaceutical Research. Volume15, Issue 6, Pages, 889-896.

Sriamornsak, P., Thirawong, N., Weerapol, Y., Nunthanid, J. \&Sungthongieen, S. (2007). Swelling and erosion of pectin matrix tablets and their impact on drug release behavior. European Journal of Pharmaceutics and Biopharmaceutics, Volume 67, Issue 1, Pages 211219. [DOI] 